\title{
Effect of arterial oxygen tension during reperfusion on myocardial recovery in patients undergoing valvular heart surgery
}

\author{
Jeong-Soo Lee ${ }^{1}$, Jong-Chan Kim ${ }^{1}$, Joo-Young Chung ${ }^{3}$, Seong-Wook Hong ${ }^{4}$, Kil-Hwan Choi ${ }^{1}$, and \\ Young-Lan Kwak ${ }^{1,2}$ \\ ${ }^{1}$ Department of Anesthesiology and Pain Medicine, ${ }^{2}$ Anesthesia and Pain Research Institute, Yonsei University College of Medicine, \\ Seoul, ${ }^{3}$ Department of Anesthesiology, Bundang Jaeseng Hospital, Seongnam, ${ }^{4}$ Department of Anesthesiology and Pain Medicine, \\ Kyungpook National University College of Medicine, Daegu, Korea
}

Background: Valvular heart surgery (VHS) utilizing cardiopulmonary bypass (CPB) is inevitably associated with ischemic-reperfusion injury, which is known to depend on oxygen tension during reperfusion. The aim of this study was to evaluate the effect of arterial oxygen tension during reperfusion on myocardial recovery in patients undergoing VHS.

Methods: Fifty-six patients undergoing isolated VHS were randomly exposed to an oxygen fraction of 0.7 (hyperoxic group, $\mathrm{n}=28$ ) or 0.5 (normoxic group, $\mathrm{n}=28$ ) during reperfusion. All patients received an oxygen fraction of 0.7 during $\mathrm{CPB}$. In the normoxic group, the oxygen fraction was lowered to 0.5 from the last warm cardioplegia administration to 1 minute after aortic unclamping, and was then raised back to 0.7. Hemodynamic data were measured after induction of anesthesia, weaning from $\mathrm{CPB}$, and sternum closure. The frequency of cardiotonic medications used during and after weaning from $\mathrm{CPB}$, and the short-term outcomes during the hospital stay were also assessed.

Results: The frequency of vasopressin and milrinone use during weaning from $\mathrm{CPB}$, but not norepinephrine, was significantly less in the normoxic group. The post-operative cardiac enzyme levels and short-term outcomes were not different between the groups.

Conclusions: Normoxic reperfusion from the last cardioplegia administration to 1 minute after aortic unclamping in patients undergoing VHS resulted in significantly less frequent use of vasopressin and inotropics during weaning from CPB than hyperoxic reperfusion, although it did not affect the post-operative myocardial enzyme release or short-term prognosis. (Korean J Anesthesiol 2010; 58: 122-128)

Key Words: Oxygen tension, Reperfusion injury, Valvular heart surgery.

Received: July 21, 2009. Revised: 1st, August 3, 2009; 2nd, August 13, 2009. Accepted: October 5, 2009.

Corresponding author: Young-Lan Kwak, M.D., Department of Anesthesiology and Pain Medicine, Yonsei University College of Medicine, 134, Shinchon-dong, Seodaemun-gu, Seoul 120-752, Korea. Tel: 82-2-2228-8513, Fax: 82-2-364-2951, E-mail: ylkwak@yuhs.ac

(c)This is an open-access article distributed under the terms of the Creative Commons Attribution Non-Commercial License (http:// creativecommons.org/licenses/by-nc/3.0/), which permits unrestricted non-commercial use, distribution, and reproduction in any medium, provided the original work is properly cited. 


\section{Introduction}

During surgery utilizing cardiopulmonary bypass (CPB), the heart is damaged not only by ischemic injury during aortic cross clamping (ACC), but also reperfusion injury after discontinuation of ACC. Especially, valvular heart surgery (VHS) requires a longer CPB duration than coronary artery bypass graft (CABG) surgery and has the possibility of reducing myocardial function by increased afterload post-operatively [1]. Thus, reducing reperfusion injury is very important in improving prognosis.

The overproduction of reactive oxygen-derived free radicals during reperfusion after ischemic injury is a major cause of the ischemic-reperfusion myocardial injury [2]. The rate of production of reactive oxygen-derived free radicals depends on the oxygen tension at reperfusion $[3,4]$. Previous studies have demonstrated that reducing the oxygen concentration in the CPB circuit to normoxic levels reduces the production of creatine kinase (CK)-MB in patients undergoing $\mathrm{CABG}$ [5]. However, monitoring devices enabling the continuous evaluation of arterial oxygen tension are not available in South Korea, and lowering oxygen tension during CPB without an appropriate real-time monitoring device for hypoxemia is unsafe. Therefore, it is difficult to maintain lower oxygen tension throughout CPB. In contrast, by lowering the oxygen fraction to 0.5 from the last warm cardioplegia administration to 1 minute after aortic unclamping, one can access hypoxic events through serial arterial blood analysis during the reperfusion period. This period is usually short, and the risk of hypoxia is low. By lowering the oxygen fraction of the reperfusate, the reactive oxygen-derived free radicals, which are the main cause of reperfusion myocardial injury that occurs with reoxygenation, can be reduced thus facilitatingmyocardial recovery during weaning from $\mathrm{CPB}$ and after surgery.

The aim of this study was to evaluate the effect of arterial oxygen tension during reperfusion on myocardial recovery in patients undergoing VHS by an analysis of hemodynamic variables, frequency of cardiotonic drug use, and short-term outcomes.

\section{Materials and Methods}

The study group was comprised of 56 consecutive patients undergoing valve replacement surgery due to valvular heart disease. The age range was from 18-75 years. The study was approved by the institutional review board and all patients gave informed consent before inclusion in the study. The preoperative evaluation included the past medical history, cardiac echogram, common blood cell count, and routine chemistries. The exclusion criteria included a left ventricular ejection fraction $<30 \%$, emergency surgery, anemia, evidence of a coagulopathy, chronic lung disease, liver and kidney disease, a history of heart surgery, and taking medications, such as heparin, coumadin, aspirin, and anti-platelet medications, within 5 days. Patients who restarted CPB after failure of the first valve replacement surgery, used mechanical support during weaning of $\mathrm{CPB}$, and had an oxygen partial pressure $<75 \mathrm{mmHg}$ with an inspired oxygen fraction of 0.4 after induction were also excluded.

Patients were randomly allocated to 2 groups based on the $\mathrm{FiO}_{2}$ at the time of last reperfusion after aortic unclamping during $\mathrm{CPB}$, as follows: group $\mathrm{FiO}_{2} 0.7$ (hyperoxic group, $\mathrm{n}=$ 28); and group $\mathrm{FiO}_{2} 0.5$ (normoxic reperfusion, $\mathrm{n}=28$ ). Only the perfusionist who controlled the $\mathrm{FiO}_{2}$ during $\mathrm{CPB}$ was aware of the patient group. The anesthetists and surgeons obtained information about the patient groups after surgery.

Lowering the oxygen fraction to 0.7 during $\mathrm{CPB}$ was determined by previous surgical experience in our hospital involving safe and lower oxygen fraction without continuous monitoring of the CPB circuit. In the current study, the oxygen partial pressure of arterial blood was $250-350 \mathrm{mmHg}$ in the hyperoxic group. The oxygen fraction of 0.7 was the minimal oxygen fraction to maintain an oxygen partial pressure $>200 \mathrm{mmHg}$. We obtained oxygen partial pressures between 300 and $350 \mathrm{mmHg}$ in the hyperoxic group, which were lower than a previous study [5]. And the oxygen fraction of 0.5 in the normoxic group was determined from preliminary studies that obtained oxygen partial pressure $150 \mathrm{mmHg}$ in the normoxic group [5].

All patients continued cardiac medications, except diuretics, and received an intramuscular injection of morphine $(0.05 \mathrm{mg} /$ $\mathrm{kg}$ ) for pre-medication 1 hour before arrival to the operating room. Upon arrival in the operating room, standard monitoring devices were applied and a radial artery catheter was inserted under local anaesthesia for continuous blood pressure monitoring. Pulmonary artery catheter (Swan-Ganz CCOmbo ${ }^{\circledR}$ $\mathrm{CCO} / \mathrm{SvO}_{2}$, Edwards Lifesciences LLC, USA) was inserted via the right internal jugular vein under local anesthesia for continuous measurement of the cardiac index (CI), mixed venous oxygen saturation $\left(\mathrm{SvO}_{2}\right)$, right ventricular ejection fraction (RVEF), and right ventricular end-diastolic volume index (RVEDVI). Cerebral oxymetry sensors (INVOS 5100TM, Somanetics, Troy, MI, USA) were applied to the forehead of the patients for continuous monitoring of regional cerebral oxygen saturation $\left(\mathrm{rSO}_{2}\right)$.

Anesthesia was induced with midazolam (2.5 mg), sufentanil $(1.5-3.0 \mu \mathrm{g} / \mathrm{kg})$, and rocuronium bromide (50 mg). After tracheal intubation, the lungs were ventilated with a tidal volume of $8-10 \mathrm{ml} / \mathrm{kg}$ at a rate of $8-12$ breaths $/ \mathrm{min}, \mathrm{a} \mathrm{FiO}_{2}$ of 0.4 , and a peak expiratory positive pressure (PEEP) of $5 \mathrm{mmH}_{2} \mathrm{O}$. Anesthesia was maintained with a continuous infusion of 
sufentanil $(0.5-1.5 \mu \mathrm{g} / \mathrm{kg} / \mathrm{h})$, vecuronium $(1-2 \mu \mathrm{g} / \mathrm{kg} / \mathrm{min})$, and sevoflurane $(1-2 \%)$.

Heparin was given at a dose of $3 \mathrm{mg} / \mathrm{kg}$ before CPB and additional heparin was administered to maintain the ACT $>$ 480 s during CPB. Tranexamic acid (2 g) was loaded before $\mathrm{CPB} ; 1 \mathrm{~g}$ was mixed to a pump priming solution and infused continuously $(6 \mathrm{mg} / \mathrm{kg} / \mathrm{h})$ until the end of surgery. All the patients began CPB with moderate systemic hypothermia, and used blood cardioplegia. The bypass circuit had a membranetype oxygenator, and the blood flow rate was $2.2-2.4 \mathrm{~L} / \mathrm{min} / \mathrm{m}^{2}$. Acid-base balance was corrected with $\alpha$-stat. Norepinephrine or sodium nitroprusside was infused to maintain the mean arterial blood pressure between 60 and $80 \mathrm{mmHg}$, and vasopressin (1 unit) was administered when using norepinephrine $>0.5 \mu \mathrm{g} / \mathrm{kg} /$ min. Packed red blood cells were transfused when the Hct was $<20 \%$ during CPB. Sufentanil ( $1.5 \mu \mathrm{g} / \mathrm{kg})$ and midazolam $(0.05$ $\mathrm{mg} / \mathrm{kg}$ ) were administered before the re-warming period.

All patients received an oxygen fraction of 0.7 during CPB. In the normoxic group, the oxygen fraction was lowered to 0.5 from the last warm cardioplegia administration to 1 minute after aortic unclamping, and then raised back to 0.7 . In both the hyperoxic and normoxic groups, arterial blood gas analysis from an arterial cannula was done and the $\mathrm{rSO}_{2}$ was recorded after the last warm cardioplegia administration. Blood cardioplegia was a mixture of crystalloid cardioplegia and the patienttalloid cin a $4: 1$ ratio. With an oxygen fraction of 0.7 , the $\mathrm{PaO}_{2}$ of blood cardioplegia was $272 \pm 72$ blood cardithe $\mathrm{PaO}_{2}$ of arterial blood was $293 \pm 93 \operatorname{arter}(\mathrm{P}=0.57)$. With an oxygen fraction of 0.5 , the $\mathrm{PaO}_{2}$ of blood cardioplegia and arterial blood was $97 \pm 48 \mathrm{mmHg}$ and $83 \pm 444 \mathrm{mmHg}$, respectively $(\mathrm{P}=0.687)$. There were no specific differences between the $\mathrm{PaO}_{2}$ of blood cardioplegia and arterial blood. Because the partial pressure of oxygen of crystalloid cardioplegia was about 160-180 mmHg, it had no specific effect on the oxygen partial pressure of the mixture of cardioplegia and the patientod cardioplegia and arterial blood. Because the parti2 of the arterial blood from the arterial cannula because there were no differences in the $\mathrm{PaO}_{2}$ between the blood cardioplegia and arterial blood, and blood cardioplegia was administered in a brief period.

Heparin was reversed with protamine $(0.5 \mathrm{mg}$ per 100 units of the initial heparin dose) after CPB. An autotransfusion system (Cell Saver ${ }^{\circledR} 5$ system; Haemonetics, MA, USA) was used and the remaining blood in the $\mathrm{CPB}$ pump was reinfused to the patient after processing by the Cell Saver ${ }^{\circledR} 5$ system. Norepinephrine was infused when the mean systemic arterial pressure (MAP) was decreased to $<60 \mathrm{mmHg}$ during and after weaning of $\mathrm{CPB}$ and vasopressin was infused continuously $(2-4 \mathrm{unit} / \mathrm{h})$ to the patients using norepinephrine over $0.3 \mu \mathrm{g} / \mathrm{kg} / \mathrm{min}$ who took a renin-angiotensin system inhibitor before surgery. Nicardipine was infused when the mean systemic arterial pressure (MAP) was increased to $>90 \mathrm{~mm} \mathrm{Hg}$. Milrinone was infused $(0.5 \mu \mathrm{g} /$ $\mathrm{kg} / \mathrm{min}$ ) after a $50 \mu \mathrm{g}$ administration to patients who had a CI $<2.0 \mathrm{~L} / \mathrm{min} / \mathrm{m}^{2}$, PCWP $>18 \mathrm{mmHg}$, and LVEF $<40 \%$ at transesophageal echocardiogram.

All patients were transferred to the ICU after surgery. Packed red blood cells were transfused when the Hct was $<25 \%$. Fresh frozen plasma was transfused to correct microvascular bleeding (bleeding $>200 \mathrm{ml} / \mathrm{h}$ for 2 consecutive hours) or in the presence of abnormal coagulation values (PT[INR] $>1.5$ ). The platelet concentrate was transfused when the platelet count was $<$ $50,000 \mathrm{~mm}^{3}$.

Hemodynamic variables, including heart rate (HR), mean arterial pressure (MAP), central venous pressure (CVP), mean pulmonary artery pressure (MPAP), and CO were recorded during induction of anesthesia, weaning from $\mathrm{CPB}$, and sternum closure. The amount and frequency of cardiotonic medications used during CPB and weaning from CPB was recorded. The hemodynamic variables were recorded 6 and 24 hours after surgery in the the ICU, and cardiac enzymes were measured 12 and 24 hours after surgery. The complications during admission were recorded. The respiratory support period and length of the stay in the ICU and general ward was also recorded.

The sample size calculation was performed based on the data of patients undergoing VHS in our hospital. The standard deviation (SD) of cardiac output was 0.7 , assuming $1 \mathrm{SD}$ has clinical significance between groups. This generated an estimate of 22 patients in each group with a $90 \%$ power to detect $1 \mathrm{SD}$ in cardiac output $\left(0.7 \mathrm{~L} / \mathrm{min} / \mathrm{m}^{2}\right)$ and an alpha level of 0.05 . Considering a $20 \%$ estimated dropout, we included 28 patients in each group. Statistical analyses were performed using SPSS 13.0 (SPSS Inc., Chicago, IL, USA). Data were assessed for normal distribution of variance with a ShapiroWilk test and Q-Q plot. All data are expressed as the number of patients or mean \pm SD. Discrete variables between the groups were compared using Chi-square test, Fisher's exact test, and continuous variables were compared using MannWhitney U test. Continuous variables between the groups, such as hemodynamic data were compared using repeatedmeasures ANOVA. Changes at time points between the groups were compared using a Bonferroni correction after the t-test. Comparing contra data (data after anesthesia induction) within the groups was done using Dunnett's test. A P value $<0.05$ was considered statistically significant.

\section{Results}

There were no significant differences in the demographic data, pre-operative medications, and types of surgery between the two groups (Table 1). 
The CPB and ACC times were similar between the two groups. The results of arterial blood gas analysis after the last warm cardioplegia administration was not significantly different, except for the low oxygen partial pressure in the normoxic group. The $\mathrm{rSO}_{2}$ result after the last warm cardioplegia administration was similar in both groups. The arterial oxygen partial pressure after an oxygen fraction of 0.4 in the normoxic group for 8 patients between 80 and $100 \mathrm{mmHg}, 15$ patients between 100 and $200 \mathrm{mmHg}$, and 5 patients $>200 \mathrm{mmHg}$. From the last warm cardioplegia administration to the 1 min after ACC off was $21.2 \pm 7.9 \mathrm{~min}$.

The frequency of using norepinephrine during weaning from CPB was not different. The dose of using norepinephrine from re-warming to weaning from $\mathrm{CPB}$ was 0.10 off was between the groups were compar and 0.14 of using nog/ $\mathrm{min}$ in the normoxic goup; there were no differences between the groups $(\mathrm{P}=0.337)$.

Table 1. Pre and Intra-operative Characteristics of Patients

\begin{tabular}{|c|c|c|c|}
\hline & $\begin{array}{l}\text { Hr group } \\
(\mathrm{n}=28)\end{array}$ & $\begin{array}{c}\text { Nr group } \\
(\mathrm{n}=28)\end{array}$ & $\mathrm{P}$ value \\
\hline Age (yr) & $53.6 \pm 10.0$ & $55.8 \pm 11.0$ & 0.443 \\
\hline Gender (M/F) & $17 / 11$ & $14 / 14$ & 0.420 \\
\hline Height (cm) & $161.8 \pm 6.9$ & $161.9 \pm 8.9$ & 0.592 \\
\hline Weight (kg) & $59.3 \pm 9.1$ & $61.9 \pm 10.5$ & 0.321 \\
\hline $\operatorname{BSA}\left(\mathrm{m}^{2}\right)$ & $1.61 \pm 0.13$ & $1.68 \pm 0.16$ & 0.084 \\
\hline $\operatorname{LVEF}(\%)$ & $63 \pm 10$ & $58 \pm 13$ & 0.156 \\
\hline \multicolumn{4}{|l|}{ Combined disease } \\
\hline Diabetes mellitus & 1 & 2 & 1.000 \\
\hline Hypertension & 3 & 8 & 0.093 \\
\hline Chronic renal failure & 2 & 1 & 0.553 \\
\hline Liver disease & 1 & 2 & 0.553 \\
\hline Atrial fibrillation & 14 & 17 & 0.420 \\
\hline \multicolumn{4}{|l|}{ Medication characteristics } \\
\hline Calcium channel blockers & 2 & 5 & 0.225 \\
\hline Beta-blockers & 3 & 8 & 0.093 \\
\hline ARA & 6 & 7 & 0.752 \\
\hline ACE-I & 7 & 6 & 0.752 \\
\hline Diuretics & 16 & 17 & 0.786 \\
\hline Digoxin & 8 & 14 & 0.101 \\
\hline \multicolumn{4}{|l|}{ Procedure } \\
\hline AVR & 7 & 11 & 0.252 \\
\hline MVR & 12 & 8 & 0.265 \\
\hline DVR & 9 & 9 & 1.000 \\
\hline
\end{tabular}

Values are the mean \pm SD or number of patients. Hr group: hyperoxic reperfusion group, $\mathrm{Nr}$ group: normoxic reperfusion group, BSA: body surface area, LVEF: left ventricular ejection fraction, ARA: angiotension receptor antagonists, ACE-I: angiotensin-converting enzyme inhibitors, AVR: aortic valve replacement, MVR: mitral valve replacement, DVR: double valve replacement.
But, the number of patients using vasopressin and milrinone was significantly less in the normoxic group. Other variables related the weaning from CPB were unremarkable (Table 2).

The changes in hemodynamic variables before and after surgery were not significantly different, except that the mean arterial pressure $1 \mathrm{hr}$ after weaning of CPB and after sternum closure in the normoxic reperfusion group were significantly lower in the normoxic goup (Table 3 ).

There were no significant differences in the cardiac enzyme levels after surgery, the period of mechanical ventilator support, the frequency of cardiotonic medications, and the length of stay in the ICU and hospital (Table 4).

\section{Discussion}

This study was designed to evaluate the effect of arterial oxygen tension during reperfusion on myocardial recovery and hemodynamic improvement and short-term outcome in patients undergoing VHS. As a result, we know that the frequency of using

Table 2. Intra-operative Data

\begin{tabular}{lrrr}
\hline & $\begin{array}{r}\text { Hr group } \\
(\mathrm{n}=28)\end{array}$ & $\begin{array}{c}\text { Nr group } \\
(\mathrm{n}=28)\end{array}$ & P value \\
\hline CPB duration (min) & $139 \pm 56$ & $142 \pm 51$ & 0.799 \\
ACC duration (min) & $99 \pm 36$ & $112 \pm 43$ & 0.253
\end{tabular}

$\mathrm{rSO}_{2}(\%)$ after last warm cardio-

plegia administration

$\begin{array}{lccc}\text { Left } & 57 \pm 9 & 53 \pm 7 & 0.112 \\ \text { Right } & 54 \pm 10 & 53 \pm 8 & 0.680\end{array}$

ABGA after last warm cardioplegia administration

$\mathrm{pH}$

$\mathrm{PaCO}_{2}$

$\begin{array}{lll}7.43 \pm 0.06 & 7.43 \pm 0.07 \quad 0.837\end{array}$

$\mathrm{PaO}_{2}$

$36 \pm 7 \quad 37 \pm 7 \quad 0.823$

$\mathrm{PaO}_{2}$

$331 \pm 43 \quad 153 \pm 77 \quad<0.001$

$\mathrm{BE}$

$-0.4 \pm 2.7 \quad 0.3 \pm 2.3 \quad 0.394$

$\begin{array}{llll}\text { Defibrillation after ACC } & 11 & 10 & 0.865\end{array}$

unclamping

Medication during CPB weaning

$\begin{array}{lrcc}\text { Norepinephrine } & 19 & 23 & 0.217 \\ \text { Milrinone } & 8 & 2^{*} & 0.036 \\ \text { Vasopressin } & 11 & 4^{*} & 0.035 \\ \text { Medication after CPB } & & & \\ \text { Norepinephrine } & 5 & 8 & 0.342 \\ \text { Milrinone } & 8 & 5 & 0.342 \\ \text { Vasopressin } & 4 & 2 & 0.669\end{array}$

Values are the mean \pm SD or number of patients. Hr group: hyperoxic reperfusion group, $\mathrm{Nr}$ group: normoxic reperfusion group, $\mathrm{CPB}$ : cardiopulmonary bypass, ACC: aortic cross clamp, $\mathrm{rSO}_{2}$ : regional cerebral oxygen saturation, ABGA: arterial blood gas analysis, BE: base excess. ${ }^{*} \mathrm{P}<0.05$ compared to hyperoxic reperfusion group. 
Table 3. Changes in Hemodynamic Parameter

\begin{tabular}{|c|c|c|c|c|c|c|}
\hline Parameters & Group & $\mathrm{T} 1$ & $\mathrm{~T} 2$ & T3 & $\mathrm{T} 4$ & T5 \\
\hline \multirow{2}{*}{$\begin{array}{c}\text { HR } \\
\text { (beats/min) }\end{array}$} & $\mathrm{Hr}$ & $69 \pm 16$ & $84 \pm 13$ & $83 \pm 10$ & $85 \pm 16$ & $79 \pm 7$ \\
\hline & $\mathrm{Nr}$ & $68 \pm 10$ & $85 \pm 17$ & $82 \pm 14$ & $87 \pm 12$ & $83 \pm 10$ \\
\hline \multirow{2}{*}{$\begin{array}{c}\mathrm{mSBP} \\
(\mathrm{mmHg})\end{array}$} & $\mathrm{Hr}$ & $77 \pm 10$ & $79 \pm 9$ & $79 \pm 9$ & $81 \pm 12$ & $78 \pm 11$ \\
\hline & $\mathrm{Nr}$ & $74 \pm 11$ & $67 \pm 10^{*}$ & $67 \pm 9^{*}$ & $75 \pm 13$ & $77 \pm 12$ \\
\hline \multirow{2}{*}{$\begin{array}{c}\text { CVP } \\
\text { (mmHg) }\end{array}$} & $\mathrm{Hr}$ & $10 \pm 4$ & $10 \pm 2$ & $10 \pm 3$ & $8 \pm 3$ & $8 \pm 4$ \\
\hline & $\mathrm{Nr}$ & $8 \pm 3$ & $9 \pm 3$ & $10 \pm 2$ & $9 \pm 2$ & $8 \pm 2$ \\
\hline \multirow{2}{*}{$\begin{array}{c}\text { mPAP } \\
(\mathrm{mmHg})\end{array}$} & $\mathrm{Hr}$ & $27 \pm 10$ & $22 \pm 5$ & $22 \pm 5$ & $20 \pm 5$ & $19 \pm 4$ \\
\hline & $\mathrm{Nr}$ & $23 \pm 7$ & $21 \pm 4$ & $21 \pm 3$ & $20 \pm 4$ & $19 \pm 5$ \\
\hline \multirow{2}{*}{$\begin{array}{c}\mathrm{CI} \\
\left(1 / \mathrm{min} / \mathrm{m}^{2}\right)\end{array}$} & $\mathrm{Hr}$ & $3.1 \pm 0.7$ & $3.1 \pm 0.7$ & $3.2 \pm 0.9$ & $3.2 \pm 0.8$ & $3.4 \pm 1.0$ \\
\hline & $\mathrm{Nr}$ & $2.9 \pm 0.7$ & $3.2 \pm 0.9$ & $3.1 \pm 0.8$ & $2.7 \pm 0.6$ & $3.0 \pm 1.0$ \\
\hline
\end{tabular}

Values are the mean \pm SD. Hr group: hyperoxic reperfusion group, Nr group: normoxic reperfusion group, T1: post-induction, T2: $1 \mathrm{~h}$ after aortic cross clamp (ACC) unclamping, T3: after sternum close, T4: $6 \mathrm{~h}$ after operation, T5: $24 \mathrm{~h}$ after operation, HR: heart rate, mSBP: mean systemic blood pressure, CVP: central venous pressure, mPAP: mean pulmonary arterial pressure, CI: cardiac index. $* \mathrm{P}<0.05$ compared to hyperoxic reperfusion group.

Table 4. Post-operative Outcomes

\begin{tabular}{lccc}
\hline & $\begin{array}{c}\mathrm{Hr} \\
(\mathrm{n}=28)\end{array}$ & $\begin{array}{c}\mathrm{Nr} \\
(\mathrm{n}=28)\end{array}$ & P value \\
\hline Ventilator care duration (hr) & $13.4 \pm 6.3$ & $16.2 \pm 7.9$ & 0.149 \\
Length of ICU stay (day) & $3.1 \pm 1.4$ & $2.9 \pm 0.8$ & 0.409 \\
$\begin{array}{l}\text { Length of post-operative } \\
\text { hospital stay (day) }\end{array}$ & $11.5 \pm 5.0$ & $11.2 \pm 3.1$ & 0.780 \\
CK-MB & & & \\
POD 1 & $51.9 \pm 40.4$ & $73.8 \pm 92.8$ & 0.266 \\
$\quad$ POD 2 & $41.0 \pm 36.7$ & $49.5 \pm 40.6$ & 0.456 \\
Pacing in ICU & 12 & 7 & 0.158 \\
Medication in ICU & 11 & 11 & 1.000 \\
$\quad$ Norepinephrine & 12 & 12 & 1.000 \\
Milrinone & 4 & 3 & 0.686 \\
Vasopressin & & & \\
\hline
\end{tabular}

Values are the mean \pm SD or number of patients. Hr group: hyperoxic reperfusion group, $\mathrm{Nr}$ group: normoxic reperfusion group, ICU: intensive care unit, CK-MB: creatine kinase-MB, POD: post-operative day.

cardiotropic drugs was decreased in the normoxic reperfusion group, but there were no specific effects in the hemodynamics and short-term outcomes and cardiac enzymes.

VHS has the possibility of reducing myocardial function by increasing afterload post-operatively, unlike the CABG surgery that improve myocardial function by increased coronary flow [1]. Also, for the reduction of myocardial injury associated with $\mathrm{CPB}$, off-pump coronary artery bypass surgery (OPCAB) can replace CABG in high-risk patients for $\mathrm{CPB}$ complications [7]. But, VHS without CPB has not been generalized. Therefore, it is clinically important to find a method that reduces myocardial injury from ischemic-reperfusion for patients undergoing VHS.
The pathophysiology of ischemic-reperfusion injury has been evaluated, and there have been two main mechanisms proposed: calcium overload and formation of oxygen free radicals $[2,8]$. The injury related overproduction of oxygen free radicals was induced by a kind of redox reaction when the myocardium was exposed to oxygen, it produced oxygen free radicals by a heavy metal-catalyzed reaction. In the first 5 min after reperfusion, oxygen derived-superoxide anion (O2-), hydroxyl radical $(\bullet \mathrm{OH}$, the most important mediator in myocardial stunning), and peroxynitrite (ONOO-) were generated. They play an important role in reperfusion injuries [9-11]. Reperfusion activates polymorphonuclear neutrophils (PMNs), and as a result there is an over-production of oxygen free radicals by PMNs [10]. At this time, oxygen free radicals react to phospholipids, proteins (contraction proteins and enzymes), and thiols (SH), and make various cellular damages. They injure the sarcolemma by forming lipid and hydrogen peroxide, and weaken the membrane bound enzyme-system [11].

The production of these free radicals is proportionate to oxygen tension (PO2) during reperfusion $[3,4]$. Methods that have been studied to reduce ischemic-reperfusion injury include lowering blood pressure during reperfusion [12] and reducing blood flow during reperfusion [13], but one of the most vigorously researched methods is controlling arterial oxygen tension in order to reduce reperfusion injury $[14,15]$. In relation to these studies, one study reported that maintaining normal arterial oxygen tension (150 mmHg) during CPB in children with cyanotic congenital heart disease resulted in dramatically reduced levels of conjugated diens, which represents the lipid peroxidation levels of the heart, compared with patients that maintained high arterial oxygen tension [16]. A following study 
reported reduced levels of CK-MB, a biomarker indicating the extent of myocardial damage, in adult patients in which arterial oxygen tension was maintained in the normal range tension during CPB and reperfusion [17]. There is also a study reporting that maintaining arterial oxygen tension between 200 and $250 \mathrm{mmHg}$ during CPB resulted in better recovery of cardiac function and effective improvement of aortic and coronary blood flow when compared with arterial oxygen tension of 400 and $450 \mathrm{mmHg}$ [15].

This study was designed to evaluate the effect of arterial oxygen tension during reperfusion on myocardial recovery in high-risk patients undergoing VHS. Previous studies maintained normal arterial oxygen tension from the start of $\mathrm{CPB}$ and directly monitored the arterial oxygen saturation or oxygen tension during CPB $[5,14]$. Unfortunately, monitoring devices enabling continuous evaluation of arterial oxygen tension are not available in South Korea, and lowering oxygen tension during $\mathrm{CPB}$ without an appropriate monitoring device is unsafe. Also, depending on the patient's condition, the risk of hypoxia can increase during rewarming periods due to increased oxygen consumption. In fact, we observed oxygen tension falling to $<100 \mathrm{mmHg}$ in $28 \%$ of patients when lowering the $\mathrm{FiO}_{2}$ to 0.5 .

The decision was thus made to observe whether controlling oxygen tension during the final reperfusion period (period of administrating warmed cardioplegia and blood and removing the ACC) can reduce myocardial injury due to ischemicreperfusion. This period is usually as short as 5-10 minutes, and the risk of hypoxia is low due to the high flow rate of the CPB machine.

The patient group that maintained a normal arterial oxygen tension of $150 \mathrm{mmHg}$ by reducing the $\mathrm{FiO}_{2}$ to 0.5 required a significantly lower dose of vasopressin and milrinone. Otherwise, hemodynamic variables and post-operative cardiac biomarkers and short-term prognosis was not different between the two groups. Drugs administered to maintain hemodynamic variables, which were primary end points, within the normal range are thought to be the reason for this lack of discrepancy.

Also, considering the fact that severe declines in systemic vascular resistance after $\mathrm{CPB}$ are closely related to disturbances in calcium homeostasis and oxidative stress due to ischemicreperfusion injury [18]; lower rates of vasopressin or milrinone administration in the normoxic group means that incidences of severe hypotension or low cardiac output were lower in this group. Therefore, it can be said that controlling oxygen tension during reperfusion is effective in cardioprotection.

The mean arterial pressures were higher in the hyperoxic group 1 hour post-CPB and sternum closure. This is thought to represent rebound hypertension occurring in more patients in the hyperoxic group when vascular tension recovers from the dilated state that occurred while weaning from CPB. The mean arterial pressure was maintained around $70 \mathrm{mmHg}$ in the normoxic group, and there was no difference in the amount of peripheral vasoconstrictor administration between the two groups. Interestingly, the number of patients requiring nicardipine due to high mean arterial pressures $>80 \mathrm{mmHg}$ was higher in the hyperoxic group (T2: 6 to $1, \mathrm{P}=0.04$; T3: 11 to $1, \mathrm{P}<0.001)$. In previous studies, biomarkers of ischemicreperfusion injury, such as $\mathrm{CK}-\mathrm{MB}$, was significantly lower in groups that maintained oxygen tension at $150 \mathrm{mmHg}$ compared with hyperoxic groups [5]. In contrast, the present study showed no difference in biomarkers or short-term prognosis between the two groups. The reason for this discrepancy seems to be related to the fact that we were not able to maintain normal arterial oxygen tension throughout CPB and therefore all patients were reperfused with high oxygen tension cardioplegia at all times. Moreover, diverse responses between patients to the change in oxygen fraction seems to be a significant factor when considering that 11 patients in the normoxic group showed oxygen tensions $>150 \mathrm{mmHg}$ right before removal of ACC despite lowering the oxygen tension to normal levels. Also, compared to oxygen tensions of $>400 \mathrm{mmHg}$ in the hyperoxic groups of previous studies $[5,15]$, the hyperoxic group of the present study showed oxygen tensions between 250 and 350 $\mathrm{mmHg}$, leading to smaller differences between the groups.

Because oxygen tensions were controlled with the beginning of administration of warmed cardioplegia, measuring the oxygen tension of cardioplegia was needed in order to measure the oxygen tension of the initial reperfusion fluid. There was no difference in oxygen tension between the cardioplegia and arterial blood, and the arterial blood was administered through the aortic cannula, thus this does not seem to have affected the accuracy of this study.

In addition, patients undergoing VHS were enrolled in this study which may lead to various degrees of myocardial injury, depending on the type of surgery, whereas previous studies were conducted in patients undergoing CABG. It increased the SD of cardiac enzymes after surgery, and the number of patients in this study was insufficient; however, the primary end point in this study was a difference of hemodynamic variables, not cardiac enzymes.

Therefore, although there were no significant improvements in levels of cardiac biomarkers or short-term prognosis, the reduced amount of administered peripheral vasoconstrictors and inotropes after only a short period of oxygen tension modulation seems to be of clinical importance. Vasoconstrictors and inotropes administered during CPB means hemodynamic instability after reperfusion, and influences the prognosis and complications of the patient post-operatively $[19,20]$.

As a result, we lowered the oxygen fraction of 0.7 to 0.5 from 
the administration of last cardioplegia to $1 \mathrm{~min}$ after ACC to reduce reperfusion injury during VHS, there were no specific effects at the hemodynamics and short-term outcome and cardiac enzymes, but the frequency using cardiotropic drugs was decreased in the normoxic reperfusion group. Reduced oxygen tension during reperfusion after aortic unclamping on CPB is thought that convenient and safe supportive management technique to reduce reperfusion injury.

\section{References}

1. Cook DJ, Housmans PR, Rehfeldt KH. Valvular heart disease: Replacement and repair. In: Kaplan's cardiac anesthesia. 5th ed. Edited by Kaplan JA, Reich DL, Lake CL, Konstadt SN: Philadelphia, Elsevier, Inc. 2006, pp 645-90.

2. Bolli R, Jeroudi MO, Patel BS, Aruoma OI, Halliwell B, Lai EK, et al. Marked reduction of free radical generation and contractile dysfunction by antioxidant therapy begun at the time of reperfusion. Evidence that myocardial "stunning" is a manifestation of reperfusion injury. Circ Res 1989; 65: 607-22.

3. Boveris A, Chance B. The mitochondrial generation of hydrogen peroxide. General properties and effect of hyperbaric oxygen. Biochem J 1973; 134: 707-16.

4. Littauer A, de Groot H. Release of reactive oxygen by hepatocytes on reoxygenation: three phases and role of mitochondria. Am J Physiol 1992; 262: G1015-20.

5. Ihnken K, Winkler A, Schlensak C, Sarai K, Neidhart G, Unkelbach $\mathrm{U}$, et al. Normoxic cardiopulmonary bypass reduces oxidative myocardial damage and nitric oxide during cardiac operations in the adult. J Thorac Cardiovasc Surg 1998; 116: 327-34.

6. Luckner G, Dunser MW, Jochberger S, Mayr VD, Wenzel V, Ulmer $\mathrm{H}$, et al. Arginine vasopressin in 316 patients with advanced vasodilatory shock. Crit Care Med 2005; 33: 2659-66.

7. Sabik JF, Gillinov AM, Blackstone EH, Vacha C, Houghtaling PL, Navia J, et al. Does off-pump coronary surgery reduce morbidity and mortality? J Thorac Cardiovasc Surg 2002; 124: 698-707.

8. Hearse DJ, Humphrey SM, Bullock GR. The oxygen paradox and the calcium paradox: two facets of the same problem? J Mol Cell Cardiol 1978; 10: 641-68.
9. Frank L, Massaro D. Oxygen toxicity. Am J Med 1980; 69: 117-26.

10. Welbourn CR, Goldman G, Paterson IS, Valeri CR, Shepro D, Hechtman HB. Neutrophil elastase and oxygen radicals: synergism in lung injury after hindlimb ischemia. Am J Physiol 1991; 260: H1852-6.

11. Gauduel Y, Menasche P, Duvelleroy M. Enzyme release and mitochondrial activity in reoxygenated cardiac muscle: relationship with oxygen-induced lipid peroxidation. Gen Physiol Biophys 1989; 8: 327-40.

12. Bopassa JC, Michel P, Gateau-Roesch O, Ovize M, Ferrera R. Lowpressure reperfusion alters mitochondrial permeability transition. Am J Physiol Heart Circ Physiol 2005; 288: H2750-5.

13. Takeo S, Liu JX, Tanonaka K, Nasa Y, Yabe K, Tanahashi H, et al. Reperfusion at reduced flow rates enhances postischemic contractile recovery of perfused heart. Am J Physiol 1995; 268: H2384-95.

14. Inoue T, Ku K, Kaneda T, Zang Z, Otaki M, Oku H. Cardioprotective effects of lowering oxygen tension after aortic unclamping on cardiopulmonary bypass during coronary artery bypass grafting. Circ J 2002; 66: 718-22.

15. Kaneda T, Ku K, Inoue T, Onoe M, Oku H. Postischemic reperfusion injury can be attenuated by oxygen tension control. Jpn Circ J 2001; 65: 213-8.

16. del Nido PJ, Mickle DA, Wilson GJ, Benson LN, Coles JG, Trusler GA, et al. Evidence of myocardial free radical injury during elective repair of tetralogy of Fallot. Circulation 1987; 76: V174-9.

17. Ihnken K, Morita K, Buckberg GD, Young HH. Studies of hypoxemic/reoxygenation injury with aortic clamping: XI. Cardiac advantages of normoxemic versus hyperoxemic management during cardiopulmonary bypass. J Thorac Cardiovasc Surg 1995; 110: 1255-64.

18. Ruel M, Khan TA, Voisine P, Bianchi C, Sellke FW. Vasomotor dysfunction after cardiac surgery. Eur J cardiothorac Surg 2004; 26: 1002-14

19. Nygren A, Thorèn A, Ricksten SE. Vasopressin decreases intestinal mucosal perfusion: a clinical study on cardiac surgery patients in vasodilatory shock. Acta Anaesthesiol Scand 2009; 53: 581-8.

20. Fleming GA, Murray KT, Yu C, Byrne JG, Greelish JP, Petracek MR, et al. Comparison of two different loading doses of milrinone for weaning from cardiopulmonary bypass. J Cardiothorac Vasc Anesth 1995; 9: 264-71. 